\title{
MENGENAL LEBIH DALAM TENTANG MANAJEMEN SUMBER DAYA MANUSIA
}

\section{Aminah Nurhidayati Maulidyah}

\author{
Program Studi Pendidikan Guru Sekolah Dasar \\ Fakultas Keguruan dan Ilmu Pendidikan \\ Universitas Nahdlatul Ulama Sidoarjo \\ Email: aminaharkenji30@gmail.com
}

\section{Pengantar}

Di zaman yang modern ini banyak sekali perusahaan atau intansi-intansi yang berada di Indonesia. Mereka (para intansi-intansi) berlomba-lomba mendirikan kinerja yang terbaik agar menarik peminat untuk berbondongbondong memakai jasa mereka (para intansi-intansi). Keinginan tersebut tumbuh dikarenakan adanya tekat yang besar untuk mensukseskan diri. Menjadikan sesuatu yang dimilikinya yang terbaik di antara yang lainnya.

Dengan belajar mengenai manajemen sumber daya manusia kita dapat mengetahui cara terbaik untuk mengelolah sumber daya manusia dan dapat memperaktikkan di dunia nyata. Adanya hal tersebut membuat para perusahawan bisa menjadikan para pekerjanya untuk bekerja secara efisien dan efektif. Juga dapat memperbaiki masalah diperusahaannya yang berhubngan dengan kinerja para pekerjanya. Sehingga perusahaannya dapat menjadi perusahaan yang dapat bersain di kaca internasional.

\section{Lingkup MSDM}

Manajemen sumber daya manusia adalah bidang yang menarik pada bisnis (Sentot Imam Wahjono). Mengapa demikian? Karena manusia bukanlah mesin atau pun robot yang tidak datap diatur dengan seenaknya tapi hal tersebut mampu untuk mengarahkan manusia dengan sesuai keinginan pengaturnya. Menurut pendapat lain manajemen sumber daya manusia ialah proses manajer untuk mengatasi permasalahan yang berada di perusahaannya yang meliputi semua tentang para pekerjanya mendapatkan hak yang seharusnya didapatkan (kesejahteraan karyawan) sehingga dapat menjalakan kewajiban yang diharapkan oleh manajer.

Sejarah adalah kejadian dan peristiwa yang benar-benar terjadi pada masa lampau (KBBI). Adanya sejarah merupakan pembelajaran untuk mengenal dan mengenang kejadian-kejadian yang terjadi di jaman dahulu dimana kita belum ada. Sehingga kita dapat memetik pelajaran berharga dari sejarah tersebut. Dalam pembahasan kali ini akan membahas bagaimana sejarah manajemen sumber daya manusia. Manajemen sumber daya manusia bukan hal baru yang ada di dunia ini. Manajemen sumber daya manusia ada dari dulu, semenjak awal kali lahirnya 
organisasi kecil. Revolusi industry Inggris adalah awal mula diperlukannya manajemen sumber daya manusia. Alasan mengapa revolusi industry Inggris menjadi awal mula munculnya manajemen sumberdaya manusia yakni keingginan industry Inggris menghasilkan produksi dengan besar-besaran tetapi dengan mempekerjakan pegawai dalam jumlah sedikit dan memanfaatkan teknologi yang dimiliki. Sehingga menjadikan keuntungan yang semakin banyak dan meningkat. Adanya penggunaan tenaga kerja yang seperti ini menjadikan para perusahawan memikirkan bagaiamana gaji, penempatan, dan kesejahteraan pekerja. Pada akhirnya diadakannya devisi "Sekretaris Kesejahteraan" (Hasibuan, 1997). Yaitu bertugas untuk memikirkan cara perumusan kebutuhan ekonomi para pekerja dan memagari para pekerja untuk tidak membentuk sebuah serikat pekerja. Revolusi ingris merambah keberbagai belahan dunia, terutama di Eropa dan Amerika Serikat pada awal abad kedua puluh. Dampak dari Revolusi Industri tersebut adalah banyak berdiri perusahaan besar dalam bidang perekonomian. Lahirnya banyak teori motivasi pada tahun 1940-an dengan Abraham H.Maslow sebagai pelopornya adalah bukti perlunya perhatian untuk manusia dalam sebuah organisasi. Kebutuhan manusia memerlukan pemenuhan secara hirarki, untuk menunjang hasil berkarya mereka. Semuanya itu memerlukan perhatian di dalam pengelolaan sumberdaya manusia.

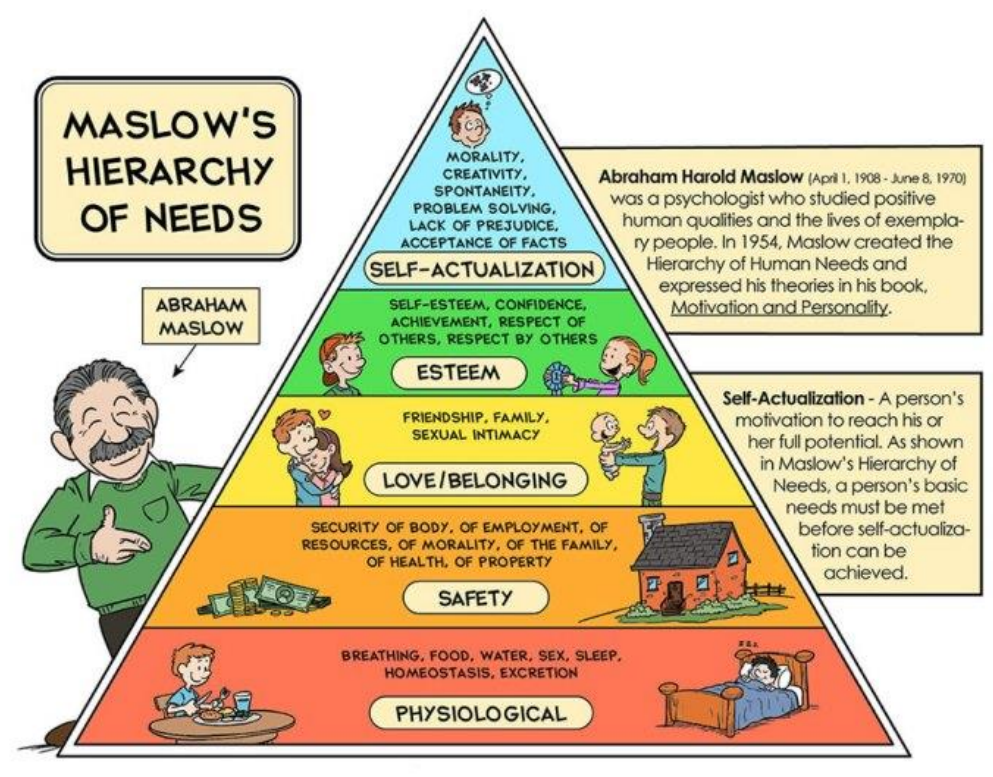

Gambar 1.1. Teori Maslow (gmpjconsulting, 2016)

Tidak ada teori dalam MSDM menurut Guest. Akan tetapi tidak dipungkiri banyak teori yang mendukung MSDM. Guest melahirkan sebuah kerangka kerja teori MSDM berdasarkan dengan pada hasil studi para ahli di Harvard University, seperti dapat dilihat dalam gambar 1.2. berikut ini: 


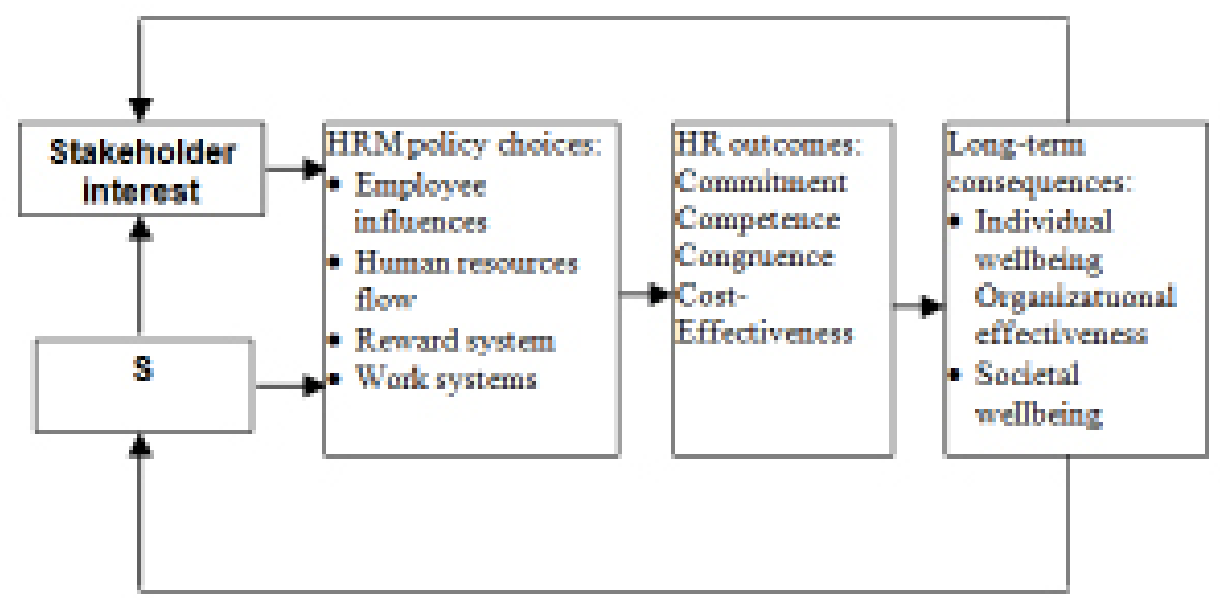

Gambar 1.2. Kerangka Kerja Teori MSDM

(dikutip dari Guest, 1987)

Basis teori MSDM dengan dilandasi diri pada sejumlah teori lintas ilmu dapat dinilai dari gambar kerangka kerja diatas. MSDM bersifat multidisipliner. Maka dari itu kita dapat menjumpai MSDM berada di disiplin ilmu ekonomi manajemen, psikologi, hukum, sosial, sejarah, serta hubungan industrial.

\section{Keberadaan MSDM}

Ada banyak fungsi dari MSDM dalam beberapa hal. pertama adalah dalam hal perencanaan untuk kebutuhan SDM adalah perencanaan dan peramalan tenaga kerja yang diinginkan dalam jangka panjang ataupun pendek dan menganalisis jabatan untuk menentukan pekerja ditemptkan di tempat yang sesuai dan dibutuhkan. kedua adalah staffing sesuai dengan kebutuhanan organisasi, dalam hal ini pekerja dikelompokkan dengan kebutuhan SDM untuk mengisi formasi yang tersedia. ketiga adalah penilaian kinerja, dalam hal tersebut terjadi setelah pekerja setelah bebrapa masa dan manajer menilai bagaiman cara bekerjanya dan bila telah memenuhi syarat ataupun melampaui akan diberikan penghargaan at kinerjanya tersebut. Terakhir dalam hal perbaikan kualitas kerja dan lingkungan kerja adalah peningkatan atau perbaikan kualitas fisik dan non-fisik lingkungan kerja.

Ada beberapa tujuan dari MSDM diantaranya tujuan organisasional dapat mengenali keberadaan manajemen sumber daya manusia dalam memberikan kontribusi pada pencapaian efektivitas. Selanjutnya tujuan fungsional bertujuan untuk mempertahankan kontribusi departemen pada tingkat yang sesuai dengan kebutuhan organisasi. Ketiga tujuan sosial yakni bertujuan untuk secara secara etis dan sosial merespon terhadap kebutuhan-kebutuhan dan tantangan-tantangan masyarakat melalui tindakan meminimasi dampak negatif terhadap organisasi. Terakhir adalahtujuan personal adalah membantu karyawan dalam mencapai tujuannya, minimal tujuan-tujuan yang dapat mempertinggi kontribusi individual terhadap organisasi. 


\section{Ramalan MSDM}

Para pekerja mencari pekerjaan kepada pengusaha berada di pasar SDM. Pasar SDM sendiri berarti wilayah untuk mencari pekerjaan untuk para calon pekerja terhadap pemberi pekerjaan. Cakupan pasar SDM memiliki beberapa factor penting, yaitu daerah geografi, pendidikan atau pengalaman/keahlihan yang dipersyaratkan, jenis usaha, persyaratan izin/sertifikat, dan keanggotaan serikat kerja. Pasar SDM internal biasanya memberikan keringaangan kepada para pekerja internal dalam hal ortasi kerja, promosi, dan pengembangan peluang lainnya. Sedangkan pasar SDM memberikan kebebasan kepada para calon pekerja untuk mendaftakan dirinya dan akan memberikan pengumunan secara terbuka juga. Akan tetapi diadakan penyaringan kepada calon pekerja yang mendaftar agar perusahaan menegtauhui usia, petgantian, dan rotasi para calon pekerja. Analisis pasar SDM bertujuan untuk meminimalisir pengunduran diri pekerja dengan memberikan konpensasi dan membuat langka yang perlu untuk menjamin pekerja sesuai dengan hasil yang diharapkan.

\section{Indeks Daya Saing 6 Negara ASEAN}

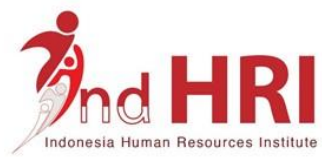

\begin{tabular}{|c|c|c|c|c|c|c|c|}
\hline & Negara & SING & MLY & THAI & IND & PHIL & VIET \\
\hline \multirow{2}{*}{\multicolumn{2}{|c|}{ Rangking }} & 2 & 18 & 32 & 37 & 47 & 56 \\
\hline & & tetap & 2 & -1 & -3 & 5 & 8 \\
\hline \multicolumn{8}{|c|}{ PilarDaya saing } \\
\hline 1 & Kelembagaan & 1 & -3 & 2 & -2 & -10 & 7 \\
\hline 2 & Infrastruktur & tetap & 1 & 4 & -6 & 1 & 5 \\
\hline 3 & MakroEkonomi & 3 & 9 & -8 & 1 & 2 & 6 \\
\hline 4 & Kesehatan dan pendidikan dasar & 1 & 9 & -1 & -6 & 6 & tetap \\
\hline 5 & Pelatihan dan pendidikan tinggi & 1 & 10 & 3 & -4 & 1 & 1 \\
\hline 6 & Efisiensi PasarBarang & tetap & 1 & tetap & -7 & -10 & -5 \\
\hline 7 & Pasar tenaga kerja & tetap & tetap & -1 & -5 & 9 & -3 \\
\hline 8 & Pengembangan PasarFinansial & tetap & -5 & -5 & -7 & 1 & 6 \\
\hline 9 & Kesiapan Teknologi & 2 & 13 & 7 & -8 & 1 & 7 \\
\hline 10 & Ukuran Pasar & -4 & tetap & 4 & 5 & 5 & 1 \\
\hline 11 & Kecanggihan bisnis & 8 & 2 & 6 & -2 & 4 & 6 \\
\hline 12 & Inovasi & tetap & 1 & 10 & 1 & 4 & 4 \\
\hline
\end{tabular}

Sumber: World Economic Forum, 2015-2016

Gambar 1.3. indeks daya saing 6 negara di ASEAN (yunustriyonggo.wordpress, 2016)

\section{Penutup}

Manajemen sumber daya manusia sendiri berarti proses manajer untuk mengatasi permasalahan yang berada di perusahaannya yang meliputi semua tentang para pekerjanya mendapatkan hak yang seharusnya didapatkan (kesejahteraan karyawan) sehingga dapat menjalakan kewajiban yang diharapkan oleh manajer. Inti dari pembahasan ini adalah adanya manajemen sumberdaya 
manusia karena revolusi industry inggris yang menyebar luas ke seluruh dunia, setiap perusahaan harus memiliki startegi dan kinerja yang bagus untuk memberikan hasil yang sangat memuaskan bagi konsumen. Apabila menginginkan kinerja para pekerja bagus kita juga akan memberikan fasilitas yang bagus pula. Ada beberapa teori diantaranya teori Abraham H.Maslow yang memberikan arahan untuk membuat kinerja (MSDM) menjadi lebih baik. 


\section{Daftar Pustaka}

Wahjono ,S,I. (2015, Sep). Manajemen Sumber Daya Manusia. Review December 29, 2018 from

https://www.researchgate.net/publication/292137504_

https://www.kbbi.web.id/sejarah diakses pada 28 desember 2018

Priono. (2010). Sejarah Lahirnya MSDM in Manajemen Sumber Daya Manusia. Sidoarjo : Zifatama Publisher.

Priono. (2008), Pengertian Lahirnya MSDM in Manajemen Sumber Daya Manusia. Sidoarjo : Zifatama Publisher.

Masram, dan Mu'ah. (2017). Fungsi MSDM in Manajemen Sumber Daya Manusi Profesional. Sidoarjo : Zifatama Publisher.

Wahjono ,S,I. (2015). Basis teori in Manajemen Sumber Daya Manusia. Jakarta : Selembah Empat.

Tim Dosen Mata Kuliah Manajemen Sumber Daya Manusia. (2019). Buku Ajar Manajemen Sumber Daya Manusia. Review December 27, 2018 from www.digilib.uwp.ac.id/digilib/files/disk1/1/--timpengaja-16-1-msdm.pdf 